\title{
DETERMINAÇÃO DA EFICÁCIA DE DIFERENTES SOLVENTES ORGÂNICOS NA DISSOLUÇÃO DOS CORANTES NATURAIS BIXINA E NORBIXINA
}

\author{
Eziel Cardoso da Silva ${ }^{1}$ \\ Marco Aurélio da Silva Coutinho ${ }^{2}$ \\ Marcio Magno Morgado Guimarães ${ }^{3}$ \\ Antonio Zilverlan Germano Matos ${ }^{4}$ \\ Abraão Leal Alves ${ }^{5}$ \\ Rondenelly Brandão da Silva ${ }^{6}$ \\ Vicente Galber Freitas Viana ${ }^{7}$
}

Resumo: Nos últimos anos, os pigmentos naturais de urucum têm sido substancialmente utilizados pelas indústrias de alimentos para dar cor a produtos tais como: massas alimentícias, cereais, produtos de panificação, gelados comestíveis, sobremesas, condimentos, etc. Dentre esses pigmentos destaca-se a bixina, um éster monometílico do ácido dicarbixílico alfa-norbixina pouco solúvel em óleo e a norbixina um caratenóide diácido carboxilico. Em virtude da crescente aplicação industrial dos corantes naturais, este trabalho teve como objetivo determinar a solubilidade desses pigmentos em diferentes solventes, por meio de espectrofotometria UV-vis. Foram preparadas soluções sob as mesmas condições, utilizando-se os solventes: acetona, álcool etílico, álcool isopropílico, dimetilsulfóxido e clorofómio. A absorbância foi medida em função do comprimento de onda de cada solução por meio da análise dos espectros de UV-Vis, na região de 800 a $200 \mathrm{~nm}$. Os dados obtidos referentes às análises no UV-Vis confirmaram a maior eficácia do Dimetilsulfóxido (DMSO) na dissolução da bixina e da acetona para o norbixina em relação aos outros solventes.

Palavras-chave: Corante; Solubilidade; Uv-visível.

\footnotetext{
${ }^{1}$ Mestrando em engenharia de Materiais/Instituto Federal de Educação, Ciência e Tecnologia do Piauí, Brasil. Email: ezielcardoso@gmail.com.

2 Mestrando em engenharia de Materiais/Instituto Federal de Educação, Ciência e Tecnologia do Piauí, Brasil. Email: marcoaureliocoutinho@hotmail.com.

3 Tutor presencial do curso de licenciatura em Química da Ead-UFPI/Universidade Federal do Piauí, Brasil. Email: marciommorgado@gmail.com.

${ }^{4}$ Mestrando em engenharia de Materiais/Instituto Federal de Educação, Ciência e Tecnologia do Piauí, Brasil. Email: zilverlan@gmail.com.

${ }^{5}$ Mestrando em engenharia de Materiais/Instituto Federal de Educação, Ciência e Tecnologia do Piauí, Brasil. Email: leal_abraao@hotmail.com.

${ }^{6}$ Co-orientador do Mestrado de engenharia de Materiais/Faculdade de Ensino Superior de Floriano, Brasil. Email: rondenelly@gmail.com.

7 Orientador do Mestrado em engenharia de Materiais/Instituto Federal de Educação, Ciência e Tecnologia do Piauí, Brasil. E-mail: galber@ifpi.edu.br.
} 